\title{
Recent developments in cataract surgery
}

As guest editor of this special series of the Annals of Translational Medicine (ATM), I would like to share with the readers at large the contributions from invited authors who provided their unique and expert perspectives on the important and critical topics of this focus series titled "Recent Developments in Cataract Surgery".

Cataract surgery is the most common surgical procedure performed in medicine. Over 20 million surgeries were carried out worldwide in the 2015, including 3.6 million in the United States of America and 4.2 million in the European Union (1). The technology progress enabled cataract surgery to become the safest and most predictable eye surgery. However, the increase in life expectancy and quality of life result in rise expectations regarding the outcomes. Presently, individuals over 70 years of age still wish to maintain an active lifestyle, including driving a car and often performing sports. Cataract surgery is no longer a procedure to eliminate the obstacle in vision providing some restoration of vision. It became a refractive procedure to eliminate all refractive errors, including astigmatism, but also in many cases managing co-existing presbyopia. Thus, this is a field of many new ideas and new developments. We still can be better and there is a demand for techniques that are even more perfect. Longer life span brings some new encounters, including more surgeries performed on patients with dementia and other comorbidities related with ageing, including glaucoma and retinal disorders. Moreover, the anticipated duration of intraocular lens (IOL) in the eye has significantly increased, thus physicochemical properties and IOL endurance should allow the IOL to keep its optical properties for up to three decades.

Congenital cataract is the leading cause of preventable blindness in children (2). Early surgical intervention may prevent deprivation amblyopia and result in good visual prognosis (3). Optimal surgical management includes microincision cataract aspiration combined with posterior capsulotomy, anterior vitrectomy and primary intraocular lens (IOL) implantation (4). Primary IOL implantation is usually performed in children older than 2 years of age. IOL implantation in children younger than 2 years of age remains a matter of controversy (5). The review by Bremond-Gignac and colleagues discusses recent developments in the diagnosis and management of congenital cataract.

It is well known that postoperative intraocular inflammation is usually more severe in younger children and it might be explained by an immature blood-ocular barrier and an underdeveloped immunosuppressive microenvironment or anterior chamber associated immune deviation (6,7). Proper understanding of these mechanisms is pivotal for optimal management of inflammatory response to surgical stimuli $(8,9)$. Postoperative complications arising from intense inflammation include formation of posterior synechiae, posterior capsule opacifications, and fibrous pupillary membrane. This, reinforced antiinflammatory medication has become the mainstay of pediatric cataract surgery (10). The study by Lai $e t$ al. presents developmental characteristics of the cytokine profile in aqueous humor and its relationship with the inflammatory response in children.

The crystalline lens in humans is characterized by life-long growth and regenerative potential what is derived from the its embryonic origin, the epidermis ectoderm, known for the ability to regenerate after injury (11). Lens epithelial cells (LEC) can proliferate and differentiate to achieve certain extent of lens regeneration, what is regulated by a variety of molecular signals and their interactions. It can be hypothesized that modifying the molecular environment can accelerate and improve the optical quality of lens regeneration. Thus, lens regeneration might be a potential option for visual function restoration after cataract surgery (12). It was argued that integrity of lens capsule, LECs and stem cells are prerequisites for functional in situ regeneration. Thus, a novel surgical strategy, minimally invasive lens-content removal surgery, was introduced (13). It included the 1-1.5 mm capsulorhexis opening located in the periphery of the anterior capsule of the lens (13). The review by Liu $e t$ al. provides an extensive update on lens regeneration in humans.

Age-related macular degeneration (AMD) is a leading cause of visual impairment in developed countries and a common ocular comorbidity in patients undergoing cataract surgery (14). Although AMD is related with inferior outcomes concerning visual acuity and patient satisfaction $(15,16)$, it generally accepted that patients with AMD benefit from cataract surgery in terms of VA and vision-related quality of life (17). The study by Taipale $e$ al . reports effects of cataract surgery on quality of life for patients with severe vision impairment due to AMD.

Moreover, intraocular magnifying devices recently developed can further increase the quality of vision in this group of patients (18). Implantable Miniature Telescope is the only approved surgical device in the US and can provide central 
vision magnification at the cost of losing peripheral vision. Meanwhile, the incision size is $7.0-7.5 \mathrm{~mm}$ and postoperative astigmatism might be an issue. IOL-VIP System and EyeMax Mono involve a smaller incision and are suitable for both phakic and pseudophakic eyes with similar magnification. The interesting development about EyeMax Mono was to provide a high-quality image in all areas of the macular extending up to $10^{\circ}$ from the fovea in case of preferred retina location changes or AMD progression (19). Recently, a prospective multicenter clinical trial about the Scharioth macula lens (SML) in previous pseudophakic eyes with AMD was published (20). Although the SML does not offer distance magnification, it can magnify $2 \times$ for objects in a range of $10-15 \mathrm{~cm}$ from the eye and can be implanted through $2.2 \mathrm{~mm}$ incision with a reduction of postoperative astigmatism. The review by Grzybowski et al. provide an in-depth analysis of different intraocular visionimproving devices in AMD.

Refraction outcome after cataract surgery depends on the precision of pre-operative measurements and calculation formulas used. The most recent formulas use new approaches, including artificial intelligence or ray-tracing analysis. Ray-tracing is method for calculation of every single ray passing through the optical system, and the refraction of rays at each optical surface is calculated using Snell's law. A map of corneal power achieved in topography or tomography can be transformed into an array of individual measurements representing a polygonal shape. Ray-tracing is employed to analyze the optical properties of every element of the eye in order to establish the performance of the entire optical system. In recent years new formulas were designed to improve the accuracy of refractive predictions, including Barrett Universal II formula, Emmetropia Verifying Optical (EVO) Formula, Kane Formula, Ladas Super Formula, Næser 2 formula, Olsen Formula, Panacea, Pearl DGS, RBF Calculator, T2 Formula, and VRF formula (21-26). The review by Savini et al. discusses recent developments in intraocular lens power calculation methods.

Although surgery is currently the only effective treatment for cataracts, the high cost and technical requirements limit its availability, especially in areas where financial resources and medical facilities are limited $(27,28)$. Thus, pharmacological therapy might become an attractive option when available. Some recent studies have reported several compounds that could prevent and dissolve protein aggregates in the lens, offering a novel anti-cataract drug screening strategy $(29,30)$. The review by $\mathrm{Xu}$ et al. presents the advances in pharmacotherapy of cataracts.

One strategy to improve the outcomes after cataract surgery is to decrease the rate of peri-operative complications. It was shown that some conditions had been related with increased risk of perioperative complications, including pseudoexfoliation (PXF) and zonular weakness, use of $\alpha 1$-blockers, dense cataracts and poor mydriasis (31). Moreover, the level of surgeons' experience and annual operation volume were recognized as factors correlating with the frequency of cataract surgery adverse events. Posterior capsule rupture, in turn, was associated with 42 -fold risk for retinal detachment and 8 -fold risk for endophthalmitis within 3 months after cataract surgery (32). It was recently showed that the New Zealand Cataract Risk Stratification (NZCRS) scoring system, that aided in identification of higher-risk cataract cases and appropriate caseto-surgeon allocation was associated with a $40 \%$ reduction in intraoperative complications (33). Thus, preoperative risk stratification seems to be an important tool to reduce intraoperative phacoemulsification complications. The study by Aaronson $e t$ al. presents an analysis of adverse effects among 14,520 eyes in relation to surgical experience.

Numerous studies have related the use of $\alpha 1$ adrenoceptor antagonists, especially tamsulosin, with the occurrence of intraoperative floppy iris syndrome (IFIS) (34). This group of drugs is used commonly in the treatment of benign prostate hypertrophy and systemic hypertension, both diseases typical for people aged over 70 years. The occurrence of IFIS might be accompanied by increased rates of multiple complications, including corneal endothelial loss, iris trauma, anterior capsule tears, posterior capsule rupture, retained nuclear fragments, vitreous loss, macular edema and postoperative ocular inflammation (35). Discontinuation of $\alpha 1$ adrenoceptor antagonists before cataract surgery can neither prevent the occurrence of IFIS nor improve the severity of IFIS (36). American Urological Association recommends that urologists avoid using tamsulosin when their patients are likely to receive cataract surgery in the near future (37). A review by Yang et al. provides an update on intraoperative floppy iris syndrome, including its pathogenesis, risk factors and management.

Endophthalmitis is a significant complication of cataract surgery, limiting the visual potential of the eye with the incidence from $0.03 \%$ to $0.7 \%$ (38). Risk factors for endophthalmitis include surgical complications (wound leak, posterior capsule rupture, vitreous loss or zonular complications), silicone IOL, clear corneal incision, age over 85 years, uncontrolled blepharitis or other ocular surface disease, diabetes mellitus, an immunocompromised state, infectious foci near the surgical site, early wound leak and no use of intracameral antibiotic. Preoperative antisepsis with povidone-iodine (PVI) significantly 
decreases the rate of bacterial endophthalmitis and is a worldwide accepted strategy (39). Moreover, dilute PVI solution has an excellent safety profile, and significantly reduces the anterior chamber contamination rate after cataract surgery (40). Interestingly, a systematic review and meta-analysis failed to find any evidence supporting the use of postoperative topical antibiotics after ocular surgery (41). The review by Sengillo et al. presents the update on the prophylaxis of postoperative Endophthalmitis and Toxic Anterior Segment Syndrome.

IOLs due to its biomaterial characteristics are prone after intraocular implantation to physico-chemical processes leading is some cases to opacification formation $(42,43)$. The hydrophobic acrylic lenses have been reported to show microvacualisation often also named as glistenings, while calcifications develop more often in hydrophilic acrylic lenses. With the prolonged expected time of IOL duration within human eye its long-term optical quality is of critical importance. Although majority of the peer-reviewed studies did not show a significant impact of glistenings and subsurface nanoglistenings on visual acuity, there are recent data about its significant effect on straylight $(42,44,45)$. Increased straylight can result in disability glare, hazy vision, and loss of contrast (46). Since straylight is not measured in standard clinical conditions, it might be easily overlooked. Thus, this area should be studied in detail in future. Moreover, since calcifications in hydrophilic materials affect visual function relatively easily, it is probably not preferable to use hydrophilic materials for IOL until the mechanism of calcification and the preventive method are elucidated. The review by Grzybowski et al. provides the updated analysis on intraocular lens opacifications and their impact on vision quality.

In recent years, lens extraction has been shown to lower the intraocular pressure (IOP) and reduce the need of IOPlowering medications in different types of primary glaucoma, especially in narrow angle glaucoma. The lens in these cases is usually abnormally thick and anteriorly positioned, thus its removal helps opening up the closed angle. It was shown that phacoemulsification alone leads to opening of the drainage angle and deepening of the anterior chamber (47), reducing the need of further glaucoma surgery. Thus, for patients with primary open glaucoma and cataract, phacoemulsification with or without combined trabeculectomy is a standard surgical option. Although the standard use of clear lens extraction in these patients is much more controversial, the EAGLE Study showed its benefits and effectiveness when compared to laser peripheral iridotomy in controlling IOP without significant increase in risks and complications (48). The review by Tsui et al. discuss the role of lens extraction in glaucoma management.

Simultaneous bilateral cataract surgery (SBCS), introduced over 60 years ago, and initially reserved to some specific indications, including eye camps and general anesthesia surgery, gained recently increasing interest. The major historical concerns against SBCS, namely the risk of bilateral endophthalmitis and the risk of postoperative refractive error, are much less limiting today (49). With the present peri-operative antiseptic policy, including the use the intracameral antibiotic and separating completely each eye surgery the risk of bilateral endophthalmitis is extremely low (50). The postoperative refractive error can be prevented by following carefully the inclusion criteria for SBCS. On the other hand, advantages of SBCS include restoring binocularity and stereopsis faster, particularly important in patients with multifocal IOLs. It should be highlighted here that corneal refractive surgeries and intravitreal injections are conducted today as standard bilateral simultaneous procedures. Moreover, SBCS is the preferred surgical approach during COVID epidemic, decreasing significantly the number of contacts between patient and medical center. The review by Singh et al. presents the evolution and recent developments in SBCS.

Living in present time, we are often oriented to the future, not to the past. Interestingly there are still many historical ophthalmic enigmas. The oldest known description of cataract surgery by Greek philosopher Chrysippus was recently described, however, the origin of cataract surgery is still mysterious (51). It was performed in ancient India, and generally it is believed that it was conducted by Sushruta around $600 \mathrm{BC}$ (52), although documented source comes from the 9th century CE and were not analyzed in detail before. The review by Leffler $e t$ al. provides in-depth analysis of original Sanskrit and ancient Greek texts to reveal the unknown aspects of early cataract surgery in ancient India and ancient Greece. It provides also overview of the existing knowledge from earliest known descriptions to phacoemulsification.

\section{Acknowledgments}

The author would like to thank all the authors that contributed to this focus series on Recent Developments in Cataract Surgery. 
Funding: This work was supported in part by Foundation for Ophthalmology Development, Poznan, Poland.

\section{Footnote}

Provenance and Peer Review: This article was commissioned by the editorial office, Annals of Translational Medicine, for the series "Recent developments in cataract surgery". The article did not undergo external peer review.

Conflicts of Interest: The author has completed the ICMJE uniform disclosure form (available at http://dx.doi.org/10.21037/ atm-20-rcs-16). The series "Recent developments in cataract surgery" was commissioned by the editorial office without any funding or sponsorship. AG served as the unpaid Guest Editor of the series. The author has no other conflicts of interest to declare.

Ethical Statement: The author is accountable for all aspects of the work in ensuring that questions related to the accuracy or integrity of any part of the work are appropriately investigated and resolved.

Open Access Statement: This is an Open Access article distributed in accordance with the Creative Commons AttributionNonCommercial-NoDerivs 4.0 International License (CC BY-NC-ND 4.0), which permits the non-commercial replication and distribution of the article with the strict proviso that no changes or edits are made and the original work is properly cited (including links to both the formal publication through the relevant DOI and the license). See: https://creativecommons.org/licenses/by-nc$\mathrm{nd} / 4.0 /$.

\section{References}

1. Grzybowski A, Kanclerz P. Recent Developments in Cataract Surgery. Current Concepts in Ophthalmology Springer 2019: 55-97.

2. Sheeladevi S, Lawrenson JG, Fielder AR, et al. Global prevalence of childhood cataract: a systematic review. Eye 2016;30:1160-9.

3. Lambert SR, Cotsonis G, DuBois L, et al. Long-term effect of intraocular lens vs contact lens correction on visual acuity after cataract surgery during infancy: a randomized clinical trial. JAMA Ophthalmol 2020;138:365-72.

4. Wang M, Xiao W. Congenital Cataract: Progress in Surgical Treatment and Postoperative Recovery of Visual Function. Eye Sci 2015;30:38-47.

5. Chen J, Chen Y, Zhong Y, et al. Comparison of visual acuity and complications between primary IOL implantation and aphakia in patients with congenital cataract younger than 2 years: a meta-analysis. J Cataract Refract Surg 2020;46:465-73.

6. Freddo TF. A contemporary concept of the blood-aqueous barrier. Prog Retin Eye Res 2013;32:181-95.

7. Wu X, Liu ZZ, Wang DN, et al. Preoperative profile of inflammatory factors in aqueous humor correlates with postoperative inflammatory response in patients with congenital cataract. Molecular Vision 2018;24:414-24.

8. Khaja WA, Verma M, Shoss BL, et al. Visual axis opacification in children. Ophthalmology 2011;118:224-5.

9. Plager DA, Lynn MJ, Buckley EG, et al. Complications in the first 5 years following cataract surgery in infants with and without intra- ocular lens implantation in the Infant Aphakia Treatment Study. Am J Ophthalmol 2014;158:892-8.

10. Grzybowski A, Tuuminem R. Should intracameral triamcinolone acetonide become a mainstay in infantile cataract surgery? Graefes Arch Clin Exp Ophthalmol 2020;258:1839-40.

11. Henry JJ, Thomas AG, Hamilton PW, et al. Cell signaling pathways in vertebrate lens regeneration. Curr Top Microbiol Immunol 2013;367:75-98.

12. Sukhija J Kaur S. Nature nurtures: lens regeneration, a breakthrough in ophthalmology. Ann Eye Sci 2017;2:17.

13. Lin $\mathrm{H}$, Ouyang $\mathrm{H}$, Zhu J, et al. Lens regeneration using endogenous stem cells with gain of visual function. Nature 2016;531:323-8

14. Mitchell P, Liew G, Gopinath B, et al. Age-related macular degeneration. Lancet 2018;392:1147-59.

15. Kanthan GL, Mitchell P, Burlutsky G, et al. Intermediate- and longer-term visual outcomes after cataract surgery: the Blue Mountains Eye Study. Clin Exp Ophthalmol 2011;39:201-6. 
16. Mönestam E, Lundqvist B. Long-term visual outcome after cataract surgery: comparison of healthy eyes and eyes with agerelated macular degeneration. J Cataract Refract Surg 2012;38:409-14.

17. Kessel L, Erngaard D, Flesner P, et al. Cataract surgery and age-related macular degeneration. An evidence-based update. Acta Ophthalmol 2015;93:593-600.

18. Grzybowski A, Wasinska-Borowiec W, Alio JL, et al. Intraocular lenses in age-related macular degeneration. Graefes Arch Clin Exp Ophthalmol 2017;255:1687-96.

19. Qureshi MA, Robbie SJ, Hengerer FH, et al. Consecutive case series of 244 age-related macular degeneration patients undergoing implantation with an extended macular vision IOL. Eur J Ophthalmol 2018;28:198-203.

20. Srinivasan S. Implantation of Scharioth macula lens in patients with age-related macular degeneration: results of a prospective European multicentre clinical trial. BMJ Open Ophthalmol 2019;4:e000322.

21. Cooke DL, Cooke TL. Comparison of 9 intraocular lens power calculation formulas. J Cataract Refract Surg 2016;42:1157-64.

22. Kane JX, Van Heerden A, Atik A, et al. Accuracy of 3 new methods for intraocular lens power selection. J Cataract Refract Surg 2017;43:333-9.

23. Shajari M, Kolb CM, Petermann K, et al. Comparison of 9 modern intraocular lens power calculation formulas for a quadrifocal intraocular lens. J Cataract Refract Surg 2018;44:942-8.

24. Melles RB, Holladay JT, Chang WJ. Accuracy of intraocular lens calculation formulas. Ophthalmology 2018;125:169-78.

25. Kane JX, Van Heerden A, Atik A, et al. Intraocular lens power formula accuracy: comparison of 7 formulas. J Cataract Refract Surg 2016;42:1490-500.

26. Melles RB, Kane JX, Olsen T, et al. Update on intraocular lens calculation formulas. Ophthalmology 2019;126:1334-5.

27. Lian RR, Afshari NA. The quest for homeopathic and nonsurgical cataract treatment. Curr Opin Ophthalmol 2020;31:61-6.

28. Wang W, Yan W, Fotis K, et al. Cataract Surgical Rate and Socioeconomics: A Global Study. Invest Ophthalmol Vis Sci 2016;57:5872-81.

29. Quinlan RA. Drug discovery. A new dawn for cataracts. Science 2015;350:636-7.

30. Skinner C, Miraldi Utz V. Pharmacological approaches to restoring lens transparency: Real world applications. Ophthalmic Genet 2017;38:201-5.

31. Kaplowitz K, Yazdanie M, Abazari A. A review of teaching methods and outcomes of resident phacoemulsification. Surv Ophthalmol 2018;63:257-67.

32. Day AC, Donachie PH, Sparrow JM, et al. The Royal College of Ophthalmologists' National Ophthalmology Database study of cataract surgery: report 1, visual outcomes and complications. Eye (Lond) 2015;29:552-60.

33. Han JV, Patel DP, Wallace HB, et al. Auckland Cataract Study III: Refining Preoperative Assessment With Cataract Risk Stratification to Reduce Intraoperative Complications. Am J Ophthalmol 2019;197:114-20.

34. Lunacek A, Mohamad Al-Ali B, Radmayr C, et al. Ten years of intraoperative floppy iris syndrome in the era of alpha-blockers. Cent European J Urol 2018;71:98-104.

35. Chatziralli IP, Sergentanis TN. Risk factors for intraoperative floppy iris syndrome: a meta-analysis. Ophthalmology 2011;118:730-5.

36. Chang DF, Osher RH, Wang L, et al. Prospective multicenter evaluation of cataract surgery in patients taking tamsulosin (Flomax). Ophthalmology 2007;114:957-64.

37. McVary KT, Roehrborn CG, Avins AL, et al. Update on AUA guideline on the management of benign prostatic hyperplasia. J Urol 2011;185:1793-803.

38. Grzybowski A, Koerner JC, George MJ. Postoperative endophthalmitis after cataract surgery: A worldwide review of etiology, incidence and the most studied prophylaxis measures. Expert Rev Ophthalmol 2019;14:247-57.

39. Grzybowski A, Kanclerz P, Myers WG. The use of povidone-iodine in ophthalmology. Curr Opin Ophthalmol 2018;29:19-32.

40. Shimada H, Nakashizuka H, Grzybowski A. Prevention and Treatment of Postoperative Endophthalmitis Using PovidoneIodine. Curr Pharm Des 2017;23:574-85.

41. Huang J, Wang X, Chen X, et al. Perioperative Antibiotics to Prevent Acute Endophthalmitis after Ophthalmic Surgery: A Systematic Review and Meta-Analysis. PLoS One 2016;11:e0166141.

42. Stanojcic N, Hull C, O'Brart DP. Clinical and material degradations of intraocular lenses: A review. Eur J Ophthalmol 2020. doi: $10.1177 / 1120672119867818$. 
43. Cari Pérez-Vives. Biomaterial Influence on Intraocular Lens Performance: An Overview. J Ophthalmol 2018;2018:2687385.

44. Matsushima H, Nagata M, Katsuki Y, et al. Decreased visual acuity resulting from glistening and sub-surface nano-glistening formation in intraocular lenses: A retrospective analysis of 5 cases. Saudi J Ophthalmol 2015;29:259-63

45. Łabuz G, Knebel D, Auffarth GU et al. Glistening Formation and Light Scattering in Six Hydrophobic- Acrylic Intraocular Lenses. Am J Ophthalmol 2018;196:112-20.

46. Łabuz G, Reus NJ, van den Berg TJ. Light scattering levels from intraocular lenses extracted from donor eyes. J Cataract Refract Surg 2017;43:1207-12.

47. Tham CC, Leung DY, Kwong YY, et al. Effects of phacoemulsification vs. combined phaco-trabeculectomy on drainage angle status in primary angle closure glaucoma (PACG). J Glaucoma 2010;19:119-23.

48. Azuara-Blanco A, Burr J, Ramsay C, et al. Effectiveness of early lens extraction for the treatment of primary angle- closure glaucoma (EAGLE): a randomised controlled trial. Lancet 2016;388:1389-97.

49. Grzybowski A, Wasinska-Borowiec W, Claoué C. Pros and cons of immediately sequential bilateral cataract surgery (ISBCS). Saudi J Ophthalmol 2016;30:244-9.

50. Arshinoff SA, Bastianelli PA. Incidence of postoperative endophthalmitis after immediate sequential bilateral cataract surgery. J Cataract Refract Surg 2011;37:2105-14.

51. Grzybowski J., Grzybowski A. Chrysippus and the First Known Description of Cataract Surgery. Medicines (Basel) 2020;7:34.

52. Grzybowski A, Ascaso J. Sushruta in $600 \mathrm{BC}$ introduced extraocular expulsion of lens material. Acta Ophthalmologica 2014;92:194-7.

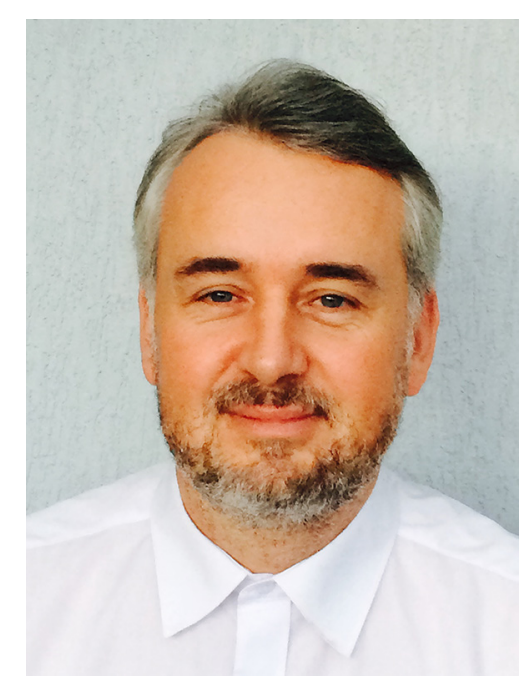

Andrzej Grzybowski

Andrzej Grzybowski, MD, PhD

Professor of Ophthalmology, Department of Ophthalmology, University of Warmia and Mazury, Olsztyn, Poland; Institute for Research in Ophthalmology, Poznan, Poland. (Email: ae.grzybowski@gmail.com)

Submitted Sep 14, 2020. Accepted for publication Oct 21, 2020.

doi: $10.21037 / \mathrm{atm}-2020$-rcs-16

View this article at: http://dx.doi.org/10.21037/atm-2020-rcs-16

Cite this article as: Grzybowski A. Recent developments in cataract surgery. Ann Transl Med 2020;8(22):1540. doi: 10.21037/ atm-2020-rcs-16 